\title{
Scale Economies and the Dynamics of Recurring Auctions ${ }^{1}$
}

\author{
THOMAS D. JEITSCHKO \\ Department of Economics \\ Texas A\&M University \\ College Station, TX 77843 \\ U.S.A.
}

thosd@acs.tamu.edu

\author{
ELMAR WOLFSTETTER
}

Institut $\mathrm{f}$. Wirtschaftstheorie I

Humboldt-Universität zu Berlin

Spandauer Str. 1

10178 Berlin, Germany

wolf@wiwi .hu-berlin.de

JULY 1998

\footnotetext{
${ }^{1}$ Earlier versions of this paper were presented at the eighth annual Lonestar's conference, Fall 1997, and the Spring 1998 Midwest Economic Theory conference. Financial support was received by the Deutsche Forschungsgemeinschaft, SFB 373 ("Quantifikation und Simulation Ökonomischer Prozesse"), HumboldtUniversität zu Berlin.
} 


\begin{abstract}
We analyze the dynamics of a game of sequential bidding in the presence of stochastic scale effects in the form of stochastic economies or diseconomies of scale. We show that economies give rise to declining expected equilibrium prices, whereas the converse is not generally true. Moreover, first- and second-price auctions are not always revenue equivalent. Indeed, economies of scale make the second-price format more profitable for the seller, whereas revenue equivalence holds in the case of diseconomies.
\end{abstract}

Keywords: auctions, procurements, sequential auctions, economies of scale. JEL classifications: D44 (Auctions) 


\section{Introduction}

Many auction settings are characterized by examples along the following lines:

- An art collector or specialized art dealer participates in auctions for expressionistic paintings from the early 1920's. As the collection grows, the "missing" pictures become more valuable, because the collection as a whole is more valuable than the sum of its parts.

- A contract to develop and supply a new generation fighter jet is auctioned recurrently. Experience gives a competitive advantage. Therefore, winning several auctions is more valuable than the sum of winning each auction alone.

- A license to supply catering services in a university cafeteria is awarded in a recurring auction. Success breeds failure. As the licensee becomes more established, organizational slack builds up.

The essential characteristic of these examples is that several units or licenses are auctioned recurrently, after some lapse of time, and that bidders' valuations are stochastically dependent across auctions.

Recurring auctions are widespread. The private firms or governments that procure certain goods or contracts, typically continue buying at certain regular time intervals. And the art dealer or collector who acquired a portfolio of items is typically a regular participant at related auctions. Also, in recurring auctions, valuations are typically stochastically dependent, due to learning, complementarities, or wear-out and organizational slack.

The present paper analyzes recurring auctions with stochastically dependent valuations in a simple framework where two prizes are auctioned in sequence to two bidders. Prior to each auction, bidders draw their private valuations for the item on the trading block. At the beginning, when the first prize is auctioned, random valuations are symmetric and independent. However, in the second auction, the probability distributions of valuations depends upon the history of either winning or losing the first auction.

Specifically, we consider two scenarios: stochastic economies and diseconomies of scale. Stochastic "economies of scale" occur if the winner of the first prize has a higher random valuation for the second prize, due to complementarities or learning effects. And "diseconomies" occur if the winner's random valuation declines, for example due to organizational slack in the framework of licensing and procurement.

We analyze the equilibrium solution of first- and second-price auctions, provide necessary and sufficient conditions for declining and increasing equilibrium prices, and for the revenue ranking of first- vs. 
second-price auction formats. In particular, we show that stochastic economies of scale give rise to declining expected prices, whereas the converse is not generally true. Standard auction formats are not revenue equivalent; economies of scale make the second-price format more profitable for the seller, whereas diseconomies preserve revenue equivalence. Nevertheless, both auction formats are efficient.

There is a sizeable literature on sequential auctions, which, however, focuses on the price sequence in the course of a multi-unit auction. This literature was stimulated by the observation of declining prices in wine auctions of identical bottles of wine (Ashenfelter (1989)), and in real estate auctions for identical condominium units (Ashenfelter and Genovese (1992)). Similar evidence for declining prices was collected for commercial real estate auctions, transponder leases, and stamp auctions, ${ }^{1}$ which gave rise to the notion of a "declining price anomaly".

Several explanations were proposed to account for this alleged anomaly. Black and de Meza (1992) show that declining prices may occur if bidders demand several units and have the option to purchase several goods. McAfee and Vincent (1993) explore the role of risk aversion as an explanation of declining prices for identical items. Bernhardt and Scoones (1994) and Engelbrecht-Wiggans (1994) show by example that prices decline if items are stochastically equivalent and each bidder demands at most one unit. In von der Fehr (1994) declining prices are a result of reduced competition in the second auction, due to costly participation. Gale and Hausch (1994) analyze auctions of stochastically equivalent items in which winners have the right to chose among the items. And Milgrom and Weber (1982) suggest that declining prices may be due to the use of agents who are instructed to win an item at any price up to a specified limit and who thus engage in non-strategic bidding.

The present paper deviates from this literature in several regards: First of all, we are not concerned with identical objects that are auctioned immediately one after another. And therefore the motivation of our analysis is not to add another explanation of the declining price sequence observed in these auctions. Instead, we are interested in understanding the dynamics of recurring auctions, when there is a sufficiently long lapse of time between subsequent rounds of auctions, and bidders do not yet know the value of the second item when they bid for the first item. Second, we consider situations where a bidder is interested in winning all auctions, unlike the more usual unit-demand assumption. And third, we are interested in modeling situations where bidders' demand is either stochastically increasing or decreasing, due to complementarities,

\footnotetext{
${ }^{1}$ Also, Beggs and Grady (1997) show declining prices relative to presale estimates in art auctions during the 1980s.
} 
learning, or wear out and organizational slack. ${ }^{2}$

The plan of the paper is as follows. In Section 2 we state the model. In Section 3 we solve the model for the case of stochastic economies and diseconomies of scale. Then, we analyze the distributions of equilibrium bids and show when and why equilibrium prices decline or increase (Section 4). Section 5 contains a revenue ranking of first-vs. second-price auctions for both scale assumptions. The paper closes with a discussion in Section 6.

\section{The Model}

Consider a sequence of two auctions, either first- or second-price, in each of which a single prize is sold to two bidders. Prior to the first auction each bidder privately observes his valuation for the first prize, $V$, but not for the second. After conclusion of the first auction, the winner is announced and, after some lapse of time, bidders privately observe their valuation for the second prize, $V_{H}$. Due to scale effects, the random variable $V_{H}$ depends upon the history $H$ of winning or losing the first auction.

The valuations of the first prize $V$ are independent random variables drawn from a support normalized to $\{0, v\}, v>0$, with $0<\rho:=\operatorname{Pr}\{V=$ $v\}<1$.

The valuation of the second prize $V_{H}$, depends on the bidders' histories. We refer to the winner of the first auction as "incumbent," whose valuation is $V_{I}$, and the loser as the "contestant," whose valuation is $V_{C}$. These valuations are stochastically independent and drawn from the same support $\{0, v\}$, but the probability of the event $V_{H}=v,(H \in\{I, C\})$ is not the same for incumbent and contestant.

Stochastic "economies" of scale occur if the incumbent has a higher probability, $\sigma$, of drawing the high valuation, i.e., $0<\sigma<\rho<1$; whereas "diseconomies" occur if $0<\rho<\sigma<1$. Of course, economies lead to an increasing, and diseconomies to a decreasing expected value of the prize.

Bidders are risk neutral and maximize the sum of the payoffs from each auction by placing any real-valued bid (no discounting). The payoffs in the second auction are

$$
U_{H}\left(V_{H}\right):=\operatorname{Pr}\{\text { winning }\}\left(V_{H}-P_{2}\right), \quad H \in\{I, C\},
$$

where $P_{2}$ denotes the price paid in that auction. The overall payoff, eval-

\footnotetext{
${ }^{2}$ von der Fehr and Riis (1998) study a somewhat similar environment; however, they focus on different issues.
} 
uated at the time of the first auction, is

$$
\begin{aligned}
U(V):= & \operatorname{Pr}\{\text { winning }\}\left(V-P_{1}\right)+\operatorname{Pr}\{\text { winning }\} E\left[U_{I}\left(V_{I}\right)\right] \\
& +(1-\operatorname{Pr}\{\text { winning }\}) E\left[U_{C}\left(V_{C}\right)\right] .
\end{aligned}
$$

Letting $\Delta$ denote the (ex ante) "value of incumbency"

$$
\Delta:=E\left[U_{I}\left(V_{I}\right)\right]-E\left[U_{C}\left(V_{C}\right)\right],
$$

the overall payoff $U$ can be written in the convenient form

$$
U(V):=\operatorname{Pr}\{\text { winning }\}\left(V-P_{1}+\Delta\right)+E\left[U_{C}\left(V_{C}\right)\right] .
$$

Ties are broken in the first auction by the flip of a fair coin, whereas, for convenience, the incumbent is favored in the case of economies and the contestant in the case of diseconomies.

The use of a discrete distribution ensures existence of a closed form solution of the asymmetric second auction in the first-price auction format. A discrete distribution entails that the equilibrium is in mixed strategies. This may be viewed as undesirable, however, the equilibrium in mixed strategies has all the desirable properties, such as monotonicity (a bidder with a higher valuation bids higher). Therefore, the use of a discrete distribution and the associated mixed strategy equilibrium should be viewed as a matter of technical convenience. Some of the technical difficulties of solving asymmetric auctions if valuations are continuous random variables are examined in Maskin and Riley (1994), (1996) and Lebrun (1996).

\section{Equilibrium Strategies}

In this section we solve the equilibrium strategies for both auction formats and both scale assumptions. We analyze the case of economies of scale in detail, and then sketch how results change for the diseconomies case.

\subsection{Dutch (First-Price) Auctions}

Since the model is solved by backward induction, first consider the second auction. Suppose there are stochastic economies of scale. Then the winner of the first auction has a higher likelihood of drawing a high valuation for the second prize. Consequently, the second auction is asymmetric. The (unique) equilibrium strategies for this auction are: 
Proposition 1 (SECond Auction) Suppose $\sigma>\rho$ (economies). In equilibrium bidders with valuation $V_{H}=0$ bid their value and bidders with $V_{H}=v$ play mixed strategies $F_{H}:[0, \rho v] \rightarrow[0,1]$. Specifically,

$$
\begin{aligned}
b_{H}(0) & =0, \quad H \in\{I, C\} \quad \text { (bidder with } V=0) \\
F_{I}(b) & =1-\frac{\rho v-b}{\sigma(v-b)} \quad \text { (incumbent with } V=v \text { ) } \\
F_{C}(b) & \left.=\frac{(1-\rho) b}{\rho(v-b)} \quad \text { (contestant with } V=v\right) .
\end{aligned}
$$

Bidders' equilibrium payoffs are

$$
U_{H}(0)=0, \quad U_{H}(v)=(1-\rho) v, \quad H \in\{I, C\} .
$$

PROOF If the rival plays the candidate equilibrium strategy, bidding below 0 is not an improvement, since it results in losing the auction. Also, bidders with valuation $V_{H}=0$ will not bid above their own value of 0 . Next consider a bidder with valuation $V_{H}=v$. If he bids $b \geq 0$, while the rival plays the strategies $F_{H}, b_{H}(0)$, his payoff is

$$
\begin{aligned}
U_{I}(v) & =(v-b)\left[(1-\rho)+\rho F_{C}(b)\right] \\
U_{C}(v) & =(v-b)\left[(1-\sigma)+\sigma F_{I}(b)\right] .
\end{aligned}
$$

Substituting the above strategies and applying the tie-breaking rule, one obtains

$$
U_{H}(v)= \begin{cases}(v-b) & \text { if } \quad b>\rho v, \\ (1-\rho) v & \text { if } b \in(0, \rho v], \\ (1-\rho) v & \text { if } b=0 \text { and } H=I, \\ \frac{1}{2}(1-\rho) v & \text { if } \quad b=0 \text { and } H=C .\end{cases}
$$

Evidently, $(1-\rho) v$ is the highest payoff that can be achieved. Therefore the best reply set of the incumbent with $V_{I}=v$ consists of all (mixed) strategies on $[0, \rho v]$. Similarly, the best replies of the contestant with $V_{C}=v$ are all (mixed) strategies on $(0, \rho v]$. Hence, the candidate strategies are mutual best replies, as asserted.

Given the equilibrium payoffs in the second auction, it is now possible to determine the equilibrium value of incumbency, denoted by $\Delta_{D}$. Since bidders with value $V_{H}=0$ have expected payoffs of 0 in the second auction, incumbency is valuable due to the positive payoff $(1-\rho) v$ obtained if $V_{H}=v$. Since $\sigma>\rho$, the incumbent is more likely to have valuation $v$ for the second prize than the contestant. Thus, after conclusion of the first auction, but before valuations of the second prize are drawn, the incumbent has a second auction expected payoff of $\sigma U_{I}(v)=\sigma(1-\rho) v$, 
whereas the contestant's expected second auction is $\rho U_{C}(v)=\rho(1-\rho) v$. Hence, by definition (2),

$$
\Delta_{D}=(\sigma-\rho)(1-\rho) v .
$$

The value of incumbency affects bidders' strategies in the first auction. Specifically, bidders account for the fact that winning the first auction not only awards the first prize, but also affects the future expected payoff. The following proposition summarizes how these considerations affect bidding in the first auction.

Proposition 2 (First Auction) Suppose $\sigma>\rho$ (economies). In equilibrium bidders with valuation $V=0$ bid the value of incumbency, bidders with $V=v$ play a mixed strategy $F:\left[\Delta_{D}, \rho v+\Delta_{D}\right] \rightarrow[0,1]$, and both continue in the second auction as summarized in Proposition 1. Specifically,

$$
\begin{gathered}
b(0)=\Delta_{D} \\
F(b)=\frac{(1-\rho)\left(b-\Delta_{D}\right)}{\rho\left(v-b+\Delta_{D}\right)} .
\end{gathered}
$$

ProOF Consider first a bidder with valuation $V=0$ who places the bid $b$ in the first auction and continues with the strategies summarized in Proposition 1. If his rival plays the candidate strategies, then using equation (3), his (overall) payoff is

$$
U= \begin{cases}\left(-b+\Delta_{D}\right) F(b)+E\left[U_{C}\left(V_{C}\right)\right] & \text { if } b>\Delta_{D}, \\ E\left[U_{C}\left(V_{C}\right)\right] & \text { if } b \leq \Delta_{D} .\end{cases}
$$

Evidently, $E\left[U_{C}\left(V_{C}\right)\right]$ is the highest payoff that he can achieve, and therefore, $b(0)=\Delta_{D}$ is a best reply, as asserted.

Next, suppose the bidder has valuation $V=v$, and places the bid $b$ while his rival uses the candidate strategies. Then, using equation (3), his overall payoff is

$$
U= \begin{cases}\left(-b+\Delta_{D}+\rho v\right)+\left(1-\rho^{2}\right) v & \text { if } b>\rho v+\Delta_{D} \\ \left(1-\rho^{2}\right) v & \text { if } b \in\left(\Delta_{D}, \rho v+\Delta_{D}\right], \\ \left(\frac{1+\rho}{2}-\rho^{2}\right) v & \text { if } b=\Delta_{D} \\ \left(\rho-\rho^{2}\right) v & \text { if } b<\Delta_{D}\end{cases}
$$

Evidently, $\left(1-\rho^{2}\right) v$ is the highest payoff he can achieve, and the best reply set is the set of all (mixed) strategies on $\left(\Delta_{D}, \rho v+\Delta_{D}\right]$. Therefore, the candidate equilibrium strategies are mutual best replies, as asserted. 
Thus, compared to a static auction, the strategies of bidders with value $V=0$, and the support of strategies of bidders with value $V=v$ are shifted by the value of incumbency, $\Delta_{D}$. In other words, in the first auction, bidders not only compete for the first prize, but also for the position of incumbency in the second auction. In the case of economies, incumbency is valuable $\left(\Delta_{D}>0\right)$. Therefore bids are higher in the first auction than they would be if there were no second auction. Nevertheless, since all bids are shifted by the same amount, the auction remains efficient.

Consider now the case of diseconomies $(\sigma<\rho)$. The second auction is nearly identical to that in the case of economies. Indeed, the strategies and payoffs are as in Proposition 1, except that $\sigma$ and $\rho$, as well as $I$ and $C$, exchange places. Thus, bidders with valuation $V_{H}=0$ bid 0 , and bidders with $V_{H}=v$ play the mixed strategies $F_{H}:[0, \sigma v] \rightarrow[0,1]$ and have expected payoffs $U_{H}$ :

$$
\begin{gathered}
F_{I}(b)=\frac{(1-\sigma) b}{\sigma(v-b)}, \\
F_{C}(b)=1-\frac{\sigma v-b}{\rho(v-b)}, \\
U_{H}(0)=0, \quad U_{H}(v)=(1-\sigma) v, \quad H \in\{I, C\} .
\end{gathered}
$$

The equilibrium strategies in the first auction are given by equation (10); however, the value of incumbency for the case of diseconomies is

$$
\Delta_{D}=(\sigma-\rho)(1-\sigma) v .
$$

The asymmetric second auction gives rise to some corollaries concerning the equilibrium distribution of bids.

COROLLARY 1 In the case of economies, an incumbent with $V_{I}=v$ bids less aggressively than a contestant with $V_{C}=v$, in the strong sense of first-order stochastic dominance:

$$
F_{C}(b)<F_{I}(b), \quad \forall b \in[0, \rho v) .
$$

Proof By (5) and (6), combined with the assumed $\sigma>\rho$, one has, $\forall b \in$ $[0, \rho v)$,

$$
\begin{aligned}
F_{I}(b) & =\frac{v(\sigma-\rho)+b(1-\sigma)}{\sigma(v-b)} \\
& >\frac{b(1-\sigma)}{\sigma(v-b)} \\
& \geq \frac{b(1-\rho)}{\rho(v-b)}=F_{C}(b),
\end{aligned}
$$

as asserted. 
Of course, having valuation $V_{H}=v$ always leads to higher bidding than $V_{H}=0$. Therefore, the less aggressive bidding by the incumbent with valuation $V_{I}=v$ is offset by the higher probability with which the incumbent draws that valuation. Interestingly, it turns out that the probability distributions of bids placed by incumbent and contestant, denoted by $G_{I}(b), G_{C}(b)$, are identical and the same as in a symmetric game in which $V_{H}=v$ is drawn with probability $\rho$.

The analogue to Corollary 1 exists, yet in the case of diseconomies it is the contestant with valuation $V_{C}=v$, instead of the incumbent with valuation $V_{I}=v$, who bids less aggressively. Thus, the following corollary applies to both scale assumptions.

COROLLARY 2 The equilibrium probability distributions of bids placed by the incumbent and the contestant, $G_{I}, G_{C}:[0, \min \{\sigma, \rho\} v] \rightarrow[0,1]$, are the same,

$$
\begin{aligned}
& G_{I}(b)=\left[(1-\sigma)+\sigma F_{I}(b)\right]=\frac{(1-\min \{\sigma, \rho\}) v}{v-b} \\
& G_{C}(b)=\left[(1-\rho)+\rho F_{C}(b)\right]=\frac{(1-\min \{\sigma, \rho\}) v}{v-b} .
\end{aligned}
$$

Moreover, $G_{I}$ and $G_{C}$ coincide with the distribution of bids that occur in a symmetric game with $\operatorname{Pr}\left\{V_{H}=v\right\}=\min \{\sigma, \rho\}$.

PROOF Substituting (5) and (6), and (5') and (6') into the above equations yields the desired results.

\subsection{English (Second-Price) Auctions}

Now consider the alternative English auction format. The following proposition gives the equilibrium strategies for both the first and the second auction. The strategies apply to both economies and diseconomies.

Proposition 3 (ENGLISH Auctions) The English auction has an equilibrium in weakly dominant pure strategies

$$
\begin{gathered}
b_{1}(V)=V+\Delta_{E} \quad \text { (first auction) } \\
b_{2}\left(V_{H}\right)=V_{H}, \quad H \in\{I, C\} \quad \text { (second auction) } \\
\Delta_{E}=(\sigma-\rho) v .
\end{gathered}
$$

PROOF As is well known, in an English auction truthful bidding is an equilibrium in (weakly) dominant strategies. This implies (11) and (12), keeping in mind that the value of winning the first auction is the value of the first prize plus the value of incumbency $\Delta_{E}$.

Next, compute $\Delta_{E}$. In the second auction a bidder's payoff is equal to zero unless two conditions are met: the bidder has valuation $V_{H}=v$, 
and his rival's valuation is $V_{H}=0$. If these requirements are met, one has $U_{I}(v)=\rho v, U_{C}(0)=0$, resp. $U_{C}(v)=\sigma v, U_{I}(0)=0$. Therefore, the equilibrium value of incumbency is $\Delta_{E}=(\sigma-\rho) v$.

Notice that in the second round of the English auction equilibrium strategies are independent of $\sigma$ and $\rho$, unlike in the Dutch auction. This plays a key role in the price formation and the revenue ranking of the English vs. Dutch auction format.

\section{Equilibrium Price Sequence}

In the course of the two auctions the expected value of the auction prize increases when there are economies of scale and decreases when there are diseconomies. In the previous section we showed how this dynamics affects bidding. Now we examine how it affects the probability distributions of equilibrium prices. Whereby declining and increasing prices are characterized either in the strong sense of first-order stochastic dominance, or in the weaker sense of differences in expected prices.

\subsection{Dutch (First-Price) Auctions}

Let $W_{1}(p), W_{2}(p)$ denote the probability distribution of the winning bid, that is the equilibrium price, in the first and second auction, respectively; and define $E\left[P_{1}\right], E\left[P_{2}\right]$ to be the associated expected prices.

THEOREM 1 (ECONOMIES) Suppose $\sigma>\rho$. The random equilibrium price declines from first to second auction in the strong sense of first-order stochastic dominance,

$$
W_{1}(p) \leq W_{2}(p), \quad \forall p,
$$

with strict inequality almost everywhere.

Proof $>$ From Corollary 2 and Proposition 1 and the fact that $\Delta_{D}>0$ one has

$$
\begin{aligned}
W_{2}(p) & =G_{I}(p) G_{C}(p) \\
& =\left(\frac{(1-\rho) v}{v-p}\right)^{2} \\
& >\left(\frac{(1-\rho) v}{v-p+\Delta_{D}}\right)^{2} \\
& =[(1-\rho)+\rho F(p)]^{2}=W_{1}(p)
\end{aligned}
$$

for all $p$ from the interior of the supports of $W_{1}$ and $W_{2}$. 
Although the average valuation increases from the first to the second auction, the Theorem demonstrates that the second prize is sold at a lower price than the first. The reason for this is that in the first auction the competition is not just for the first prize, but also for the position of incumbency in the second auction. The latter effect increases competition in the first auction so that prices decline in the course of the two auctions.

As prices decline in the case of economies, one might conjecture that diseconomies should give rise to increasing equilibrium prices. After all, diseconomies make incumbency undesirable, which lowers bidding in the first auction.

Surprisingly, this conjecture is not generally correct. Indeed, equilibrium prices decline also in the case of diseconomies, unless the incumbent's probability of drawing a high valuation $(\sigma)$ is "small" compared to the initial probability $\rho$. Indeed, as illustrated in Figure 1, prices decline for all combinations of $\sigma$ and $\rho$ except those in the shaded area.

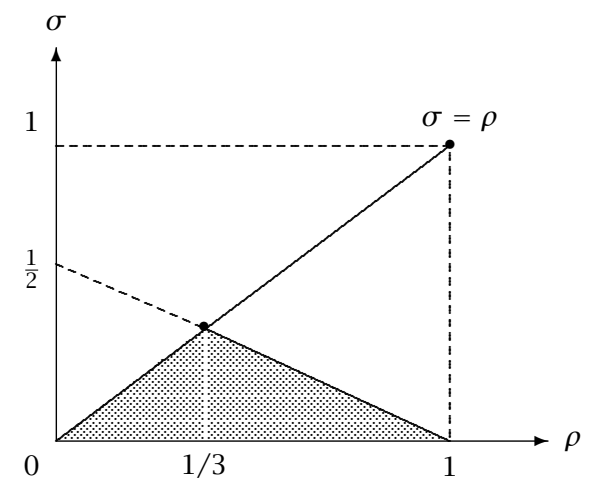

Figure 1: Declining and Increasing Prices

THEOREM 2 (DISECONOMIES) Suppose $\sigma<\rho$. Then, expected equilibrium prices decline if $\sigma>\frac{1-\rho}{2}$, and increase if $\sigma<\frac{1-\rho}{2}$,

$$
E\left[P_{1}^{D}\right] \gtreqless E\left[P_{2}^{D}\right] \Longleftrightarrow \sigma \gtreqless \frac{1-\rho}{2} .
$$

Proof Similar to the proof of Theorem 1 for the case of diseconomies,

$$
\begin{gathered}
W_{2}(p)=\left(\frac{(1-\sigma) v}{v-p}\right)^{2}, \quad p \in[0, \sigma v] \\
W_{1}(p)=\left(\frac{(1-\rho) v}{v-p+\Delta_{D}}\right)^{2}, \quad p \in\left[\Delta_{D}, \rho v+\Delta_{D}\right] .
\end{gathered}
$$


Hence, using ( $\left.8^{\prime}\right)$ and defining $\phi(\sigma):=E\left[P_{1}^{D}\right]-E\left[P_{2}^{D}\right]$, one obtains ${ }^{3}$

$$
\begin{aligned}
E\left[P_{2}^{D}\right] & =\sigma^{2} v \\
E\left[P_{1}^{D}\right] & =\rho^{2} v+\Delta_{D}=\left(\rho^{2}+(\sigma-\rho)(1-\sigma)\right) v \\
\phi(\sigma) & =(\sigma-\rho)(1-\rho-2 \sigma) v .
\end{aligned}
$$

Since $\sigma<\rho, \phi(\sigma) \gtreqless 0$ iff $2 \sigma \gtreqless 1-\rho$.

Another difference is that in the case of diseconomies one cannot rank the random equilibrium prices by first-order stochastic dominance, which is why Theorem 2 refers only to expected prices. This follows from the fact that the distribution function $W_{2}(p)$ is below $W_{1}(p)$ for all $p<0$, but algebraic manipulation reveals a jump above $W_{1}(p)$ at $p=0$. Clearly, this violates first-order stochastic dominance.

The reason for declining expected equilibrium prices for large $\sigma$ is the way in which $\sigma$ affects the equilibrium prices in the two consecutive auctions. Increasing $\rho$ while leaving $\sigma$ unchanged, $E\left[P_{2}^{D}\right]$ remains the same, whereas $E\left[P_{1}^{D}\right]$ is affected in two ways: First, it leads to a higher probability of bidders having valuation $V=v$ for the first prize, which yields a marginal increase of $E\left[P_{1}^{D}\right]$ by $2 \rho v$. Second, it decreases the value of incumbency, which leads to a marginal decrease of $E\left[P_{1}^{D}\right]$ by (1$\sigma) v$. Clearly the greater $\sigma$ is, the smaller the impact of the second effect is, so that the first effect dominates. This results in declining expected equilibrium prices for sufficiently large $\sigma$.

\subsection{English (Second-Price) Auctions}

Unlike the Dutch auction, the evolution of prices in the English auction is unambiguously governed by the scale assumption, as summarized in the following Theorem.

THEOREM 3 In the English auction, the expected equilibrium price decreases if there are economies, and increases if there are diseconomies

$$
E\left[P_{1}^{E}\right] \gtreqless E\left[P_{2}^{E}\right] \Longleftrightarrow \sigma \gtreqless \rho .
$$

Proof Recall from Proposition 3 that $P_{2}^{E}$ is equal to $v$ iff $V_{I}=V_{C}=v$, and equal to 0 otherwise; similarly, $P_{1}^{E}$ is equal to $v+\Delta_{E}$ iff both bidders draw the valuation $V=v$ and equal to $\Delta_{E}$ otherwise. Therefore,

$$
\begin{gathered}
E\left[P_{1}^{E}\right]=\left(1-\rho^{2}\right) \Delta_{E}+\rho^{2}\left(v+\Delta_{E}\right)=\rho^{2} v+(\sigma-\rho) v \\
E\left[P_{2}^{E}\right]=\rho \sigma v,
\end{gathered}
$$

and the assertion follows immediately.

\footnotetext{
${ }^{3}$ To compute $E\left[P_{1}^{D}\right]$, note that $W_{1}(p)$ has a mass point at $p=\Delta_{D}$.
} 


\section{Revenue Ranking}

Which auction format-either Dutch or English - gives the seller the higher expected revenue? While in the second auction the English auction is unambiguously more profitable to the seller, the revenue ranking in the first auction depends upon the scale assumption. Altogether, the first-round weighs sufficiently strong to make the scale assumption pivotal for the ranking of the seller's overall expected revenue. As a first step we consider the ranking of expected revenues in each of the two auctions, and then proceed to rank the seller's overall expected revenues.

Proposition 4 (SECOND AUCTION REVENUE) The seller's equilibrium expected revenue in the second auction is higher in the English than in the Dutch auction:

$$
E\left[P_{2}^{D}\right]<E\left[P_{2}^{E}\right],
$$

regardless of whether there are economies or diseconomies.

Proof Recall from (14), $E\left[P_{2}^{D}\right]=\sigma^{2} v$ if $\sigma<\rho$. Similarly, $E\left[P_{2}^{D}\right]=\rho^{2} v$ if $\sigma>\rho$. Finally, from (17), $E\left[P_{2}^{E}\right]=\sigma \rho v$. Hence,

$$
E\left[P_{2}^{D}\right]=(\min \{\sigma, \rho\})^{2} v<\sigma \rho v=E\left[P_{2}^{E}\right],
$$

as asserted.

The key to understanding the superiority of the English auction in the second round of bidding is Corollary 2. There it is shown that in the Dutch auction the distribution of bids, and hence the seller's expected revenue, is the same as in a symmetric game in which both incumbent and contestant draw the high valuation $V_{H}=v$ with the smaller probability, $\operatorname{Pr}\left\{V_{H}=v\right\}=\min \{\sigma, \rho\}$. Of course in a (static) symmetric auction, Dutch and English formats yield the same expected revenues. However, if either $\sigma>\rho$ (economies) or $\sigma<\rho$ (diseconomies), one of the bidders has a higher chance of drawing $V_{H}=v$, while strategies in the English format are unaffected by variations in $\sigma$ or $\rho$ (see (12)). Therefore, compared to the symmetric English auction, one bidder's average bid is higher which raises the seller's expected revenue. This explains why the English auction is superior to the seller, for economies and diseconomies alike.

However, this unconditional superiority of the English auction does not extend to the first round of bidding.

Proposition 5 (FIRST AUCTION REVENUE) The seller's equilibrium expected revenue in the first auction is higher in the Dutch auction if there are diseconomies, and higher in the English auction if there are economies, i.e.,

$$
E\left[P_{1}^{D}\right] \gtreqless E\left[P_{1}^{E}\right] \Longleftrightarrow \sigma \lesseqgtr \rho .
$$


Proof In the case of diseconomies $(\sigma<\rho)$, (15) and (16) yield

$$
\begin{aligned}
E\left[P_{1}^{D}\right] & =\left(\rho^{2}+(\sigma-\rho)(1-\sigma)\right) v \\
& >\left(\rho^{2}+(\sigma-\rho)\right) v=E\left[P_{1}^{E}\right] .
\end{aligned}
$$

Similarly, if $\sigma>\rho$, using $W_{1}$ from the proof of Theorem 1 one has

$$
\begin{aligned}
E\left[P_{1}^{D}\right] & =\left(\rho^{2}+(\sigma-\rho)(1-\rho)\right) v \\
& <\left(\rho^{2}+(\sigma-\rho)\right) v=E\left[P_{1}^{E}\right] .
\end{aligned}
$$

To understand this result, note first that the auctions are equivalent to a static symmetric auction in which bidders draw either the valuation $\Delta$ or $v+\Delta$. If the values of incumbency, $\Delta$, were the same, the seller's expected revenues would also be the same, by the Revenue Equivalence Theorem. However, from equations (8), (8'), and (13) the values of incumbency differ as follows

$$
\Delta_{E} \gtreqless \Delta_{D} \Longleftrightarrow \sigma \gtreqless \rho .
$$

Of course, the seller's expected revenue is increased if bidders' valuations are uniformly increased. Hence, the auction with the higher $\Delta$ also yields the higher expected revenue.

The reason for (18), is that in the second auction of the Dutch format both the incumbent and the contestant benefit from the asymmetry of the auction (cf. Corollary 2), whereas in the English format it is only the incumbent in the case of economies and the contestant in the case of diseconomies. A straightforward implication of this is that the value of incumbency is greater in absolute value in the English auction.

We now turn to the overall expected revenues for the two formats. To this end, define $\Pi:=E\left[P_{1}\right]+E\left[P_{2}\right]$ to be the seller's overall expected revenue.

THEOREM 4 (REVENUE RANKING) The seller's overall equilibrium expected revenue is higher in the English than in the Dutch format if and only if there are economies, otherwise the auction formats are revenue equivalent, i.e.,

$$
\begin{aligned}
& \Pi^{E}>\Pi^{D} \Longleftrightarrow \sigma>\rho, \\
& \Pi^{E}=\Pi^{D} \Longleftrightarrow \sigma \leq \rho .
\end{aligned}
$$

Proof The superiority of the English auction in the case $\sigma>\rho$ (economies) follows from the fact that the English auction gives rise to higher revenues in both auctions, as shown in Propositions 4 and 5. 
In turn, if $\sigma<\rho$ (diseconomies), one obtains:

$$
\begin{aligned}
\Pi^{D}-\Pi^{E} & =\left(E\left[P_{1}^{D}\right]-E\left[P_{1}^{E}\right]\right)+\left(E\left[P_{2}^{D}\right]-E\left[P_{2}^{E}\right]\right) \\
& =(\sigma-\rho) v[(1-\sigma)-1]+\sigma(\sigma-\rho) v \\
& =0,
\end{aligned}
$$

as asserted.

\section{Conclusion}

Many, if not most, auctions are recurring events. Thus, bidders may have reasonable expectations of meeting current opponents again at a future auction, under terms that are affected by the outcome of previous auctions. In many such instances a bidder who has won a previous auction may experience either an increase or a decrease of their random valuation in subsequent auctions, due to complementarities, learning effects, or wear-out and organizational slack. The theme of this paper is to study how this dynamic structure affects bidders' strategies, equilibrium prices, and equilibrium revenues in the two most common auction formats.

It is shown that stochastic scale effects may intensify competition in the first auction, even if winning the first auction is unfavorable due to the presence of diseconomies of scale. In these instances this results in declining prices. Moreover, first- and second-price auctions are generally not revenue equivalent. Economies of scale make the second-price format more profitable for the seller. However, revenue equivalence is preserved in the case of diseconomies.

Although the model employs a highly stylized two-state distribution, the main results and intuition extend to more general models. However, the extension to more than two rounds of bidding poses intricate issues, unless one assumes that stochastic scale effects occur only once and for all. If repeated scale effects occur, the trade-offs of winning and losing an auction become fairly complex and the equilibrium price sequence may fail to be monotone.

\section{References}

Ashenfelter, O. (1989). How auctions work for wine and art. Journal of Economic Perspectives, 3:23-36.

Ashenfelter, O. and Genovese, D. (1992). Testing for price anomalies in real-estate auctions. American Economic Review (Papers and Proceedings), 80:501-505. 
Beggs, A. and Graddy, K. (1997). Declining values and the afternoon effect: Evidence from art auctions. Rand Journal of Economics, 28:544-565.

Bernhardt, D. and Scoones, D. (1994). A note on sequential auctions. American Economic Review, 84:653-657.

Black, J. and de Meza, D. (1992). Systematic price differences between successive auctions are no anomaly. Journal of Management Strategy, 1:607-628.

Engelbrecht-Wiggans, R. (1994). Sequential auctions of stochastically equivalent objects. Economics Letters, 44:87-90.

Gale, D. and Hausch, D. (1994). Bottom-fishing and declining prices in sequential auctions. Games and Economic Behavior, 7:318-331.

Lebrun, B. (1996). Existence of equilibrium in first price auctions. Economic Theory, 7:421-443.

Maskin, E. and Riley, J. G. (1994). Equilibrium in sealed high bid auctions. Working paper, Harvard University and UCLA.

Maskin, E. and Riley, J. G. (1996). Asymmetric auctions. Working paper, Harvard University.

McAfee, R. P. and Vincent, D. (1993). The declining price anomaly. Journal of Economic Theory, 60:191-212.

Milgrom, P. and Weber, R. (1982). A theory of auctions and competitive bidding, II. Disc. paper, Northwestern University.

von der Fehr, N.-H. M. (1994). Predatory bidding in sequential auctions. Oxford Economic Papers, 46:345-356.

von der Fehr, N.-H. M. and Riis, C. (1998). Option values in sequential markets. Disc. paper, Department of Economics, University of Oslo. 